\title{
A DEMANDA REGIONAL E A OFERTA DO ENSINO SUPERIOR EM UMA CIDADE MÉDIA NO ESTADO DE MATO GROSSO DO SUL: DOURADOS
}

\author{
Bruno Bomfim Moreno ${ }^{1}$ \\ Maria José Martinelli Silva Calixto ${ }^{2}$
}

\section{RESUMO}

Este texto visa analisar a oferta do ensino superior em Dourados-MS e sua relação/articulação com sua rede urbana. Com tal propósito, foram utilizados os dados do Sistema e-MEC, dos bancos de dados dos sistemas acadêmicos das Instituições de Ensino Superior (IES) de Dourados e das Avaliações Institucionais (auto avaliações). Além disso, a quantidade de veículos de transporte coletivo estudantil interurbano estacionada nos pátios das instituições foi considerada como dado da pesquisa. A análise desses elementos contribuiu para comprovar que a oferta do ensino superior em Dourados não se assegura estritamente por demandas locais, mas a partir da articulação da demanda local com a regional.

Palavras-Chave: ensino superior; rede urbana; demandas regionais; centralidade; fluxos regionais.

\section{ABSTRACT}

This text aims to analyze the offer of higher education in Dourados-MS and its relation/articulation with its urban network. With this purpose, the data of the e-MEC System, the databases of the academic systems of Higher Education Institutions (IES) of Dourados and the Institutional Assessments (self-evaluations) were used. In addition, the number of intercity student collective transportation vehicles parked in the institutions courtyards was considered as a research data. The analysis of these elements contributed to prove that the supply of higher education in Dourados is not strictly ensured by local demands, but is based on the articulation of local and regional demand.

Keywords: higher education; Urban network; Regional demands; Centrality; Regional Flows.

\footnotetext{
${ }^{1}$ Universidade Estadual de Goiás. E-mail: morenobruno@yahoo.com.br

2 Docente do Programa de Pós-Graduação em Geografia da Universidade Federal da Grande Dourados.mjmartinelli@yahoo.com.br

Estudos Geográficos, Rio Claro, 15(1): 62-87, jan./jun. 2017 (ISSN 1678-698X)

http://www.periodicos.rc.biblioteca.unesp.br/index.php/estgeo 


\section{INTRODUÇÃO}

A cidade de Dourados-MS localiza-se na porção centro-sul do estado de Mato Grosso do Sul, posição que a privilegia nas interações com outros centros urbanos. Destaca-se pela dinâmica que as atividades comerciais e de serviços exercem sobre a demanda regional, intensificando os fluxos em direção a esse centro e expressando uma condição de centralidade, que tem na porção sul do estado sua principal área de influência.

O ensino superior contribui para a expressão dessa centralidade, à medida que possibilita e assegura as articulações entre Dourados e os demais centros urbanos da região. Assim, na busca de analisar tais relações, o texto foi dividido em três partes.

$\mathrm{Na}$ primeira parte, procurou-se estabelecer um diálogo com autores que se dedicaram a entender Dourados e sua condição regional. Na segunda parte, considerando a rede urbana, são apresentados os dados relativos ao ensino superior para que, na terceira parte, constatada a condição regional diferenciada de Dourados, seja analisada o papel da rede urbana na constituição da oferta do ensino superior, assim como o fluxo de estudantes.

\section{APONTAMENTOS INICIAIS SOBRE A CONDIÇÃO REGIONAL DE DOURADOS-MS}

Segundo o IBGE/REGIC - Regiões de Influência das Cidades (2008), Dourados é uma Capital Regional C, subordinada a Campo Grande, capital do estado do estado de Mato Grosso do Sul, e classificada como uma Capital Regional A (que se subordina a São Paulo, Grande Metrópole Nacional). O município de Dourados possui 196.035 habitantes (IBGE, 2010), o segundo maior em tamanho demográfico no estado de Mato Grosso do Sul.

No que se refere à rede urbana (Figura 1), estabelece relação direta com 21 centros e, quando consideradas as relações indiretas, acrescentam-se mais 12 centros em sua área de influência, totalizando 33 centros, dois deles do estado do Paraná - Terra Roxa e Guaíra. Destacam-se na rede: Mundo Novo, Naviraí e Ponta Porã, centros que são classificados como Centros de Zona A.

Se a rede urbana de Dourados for pensada em termos demográficos, verificase que a população é de 590.827 habitantes; quando somada à população de Dourados, chega-se a um total de 786.862 habitantes sendo que, desse total, $79,33 \%$ (624.247) vivem nas cidades e 20,98\% (153.999) no campo. A população dos centros da rede urbana de Dourados, excluindo os municípios do estado do Paraná, representa $30,19 \%$ da população estadual.

Apesar da análise presente neste texto ser referenciada pelo recorte analítico da rede urbana regional, adianta-se que tal proposição não foi estabelecida com o intuito de aprisionar a discussão. Assim, a esse respeito, propõe Sposito:

Nada pode ser explicado apenas numa escala, mesmo que estejamos nos referindo à escala internacional. Toda compreensão requer a articulação entre as escalas, ou seja, a avaliação dos modos, intensidades e arranjos, segundo os quais os movimentos se realizam e as dinâmicas e os processos se desenvolvem, combinando interesses e administrando conflitos que não se 
restringem a uma parcela do território, mesmo quando os sujeitos sociais, que têm menor poder aquisitivo, parecem atados a territórios relativamente restritos. (2011, p.130)

Ainda nessa perspectiva metodológica, é válido apontar que esta proposição também se apoia nas ideias trazidas por Calixto (2011) que, ao analisar a constituição da centralidade de Dourados, parte do

[...] entendimento de que esse processo só pode ser compreendido na sua relação com o outro, pois o dinamismo de um centro acaba, de certa forma, por 'cercear' o dinamismo dos demais centros do seu entorno. De modo contraditório, a aparente cooperação entre os centros urbanos é reveladora de maior diversidade entre eles, sugerindo uma relação dialética entre complementaridade e diversidade. (2011, p.60-1).

Para compreender o papel do ensino superior em Dourados, não se poderia restringir a análise apenas à oferta deste centro urbano, mas procurar entendê-lo na sua relação com a oferta de outros centros de sua área de influência ou da área em que, a partir do ensino superior, esse centro regional estabelece fluxos.

Figura 1. Rede urbana de Dourados-MS (2008)

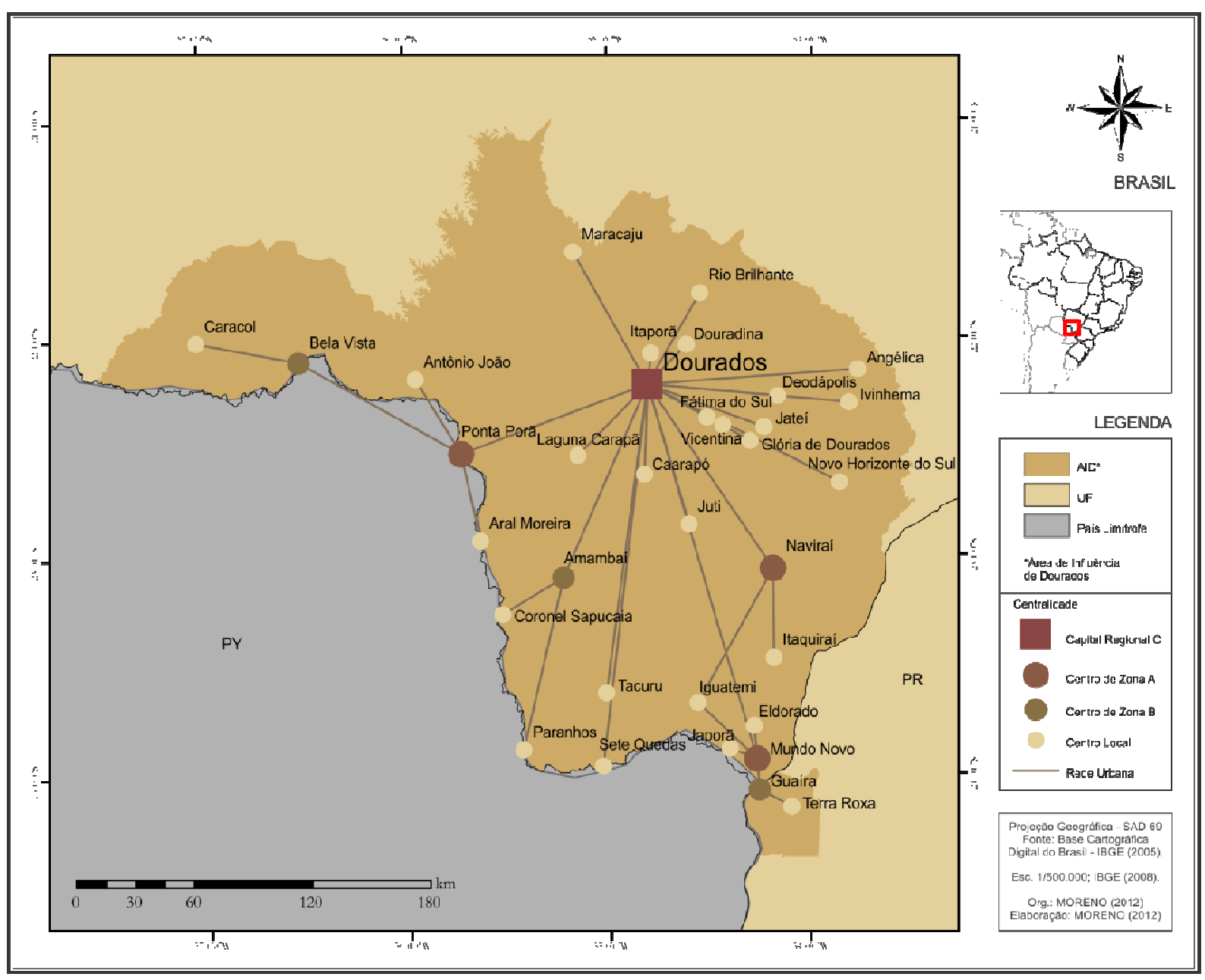

Estudos Geográficos, Rio Claro, 15(1): 62-87, jan./jun. 2017 (ISSN 1678-698X) 
Nesse sentido, a "delimitação"3 desse recorte é importante, pois não é possível pensar o ensino superior sem considerar o deslocamento diário de pessoas e a própria mobilidade/migração para centros que concentram esse serviço, no caso específico abordado aqui, sobretudo a mobilidade em direção a Dourados, ponto de articulação e de papéis de intermediação na rede urbana, conforme as pesquisas de Silva (2010), Yamashita (2011) Calixto (2011) e Moreno (2013).

As cidades médias, cuja construção conceitual tem ganhado contornos importantes com as pesquisas desenvolvidas pela Rede de Pesquisadores sobre Cidades Médias - ReCiMe ${ }^{4}$, aparecem como centros que concentram e ofertam, dentre outros, significativo número de cursos de graduação e pós-graduação. Sob essa perspectiva, considera-se a ideia de que a importância de uma cidade média tem "[...] relação direta com a área sobre a qual ela é capaz de exercer influência ou, em outras palavras, a área a partir da qual alguém está disposto a se deslocar até uma cidade média para nela ter acesso ao consumo de bens e serviços." (SPOSITO et al. 2007, p.37).

Tratando-se de Dourados, pode-se afirmar que a dinamização da economia regional se deu a partir da incorporação de tecnologias na produção agropecuária, impulsionada pelas demandas do mercado internacional. Essa produção, cada vez mais pautada no uso da ciência, da técnica e da informação desencadeou especializações para atender às atividades ligadas a esse setor.

Nesses termos, a cidade se torna centro de "drenagem e consumo da renda fundiária" (CORRÊA, 2007a), e se instaura no campo um processo em que a "[...] agropecuária globalizada é um dos vetores da reorganização produtiva do território [...]" (ELIAS, 2007, p.114). Ainda para Elias, nas áreas em que se dá a difusão do agronegócio, "[...] processa-se uma reestruturação da economia e do espaço, resultando no incremento da urbanização [...]" $(2007,114)$.

Essa especialização funcional ${ }^{5}$, determinada pelas atividades econômicas reverbera, de forma significativa, na oferta dos cursos de graduação, uma vez que o perfil produtivo passa a influenciar na criação de cursos de nível superior, nesse caso, ligados à área de conhecimento vinculado ao campo, mais especificamente, às atividades agropecuárias. Isso acaba contribuindo com a qualificação de mão de obra que passa a atuar, não restritamente, em toda a região, alterando as relações de trabalho e de produção.

Ao se referir à caracterização das cidades médias, pelo enfoque funcional, Sposito (2001) resume que a identificação delas

\footnotetext{
${ }^{3}$ Vale reforçar que a proximidade tem um papel primordial à realização dos deslocamentos para a efetivação do consumo na cidade média. "Esses fluxos definem-se, assim no âmbito da região e marcam e são marcados pela existência de um espaço de continuidade territorial, cuja configuração é a de uma área." (SPOSITO et al. 2007, 49).

${ }^{4}$ Para maiores informações sobre a Rede de Pesquisadores sobre Cidades Médias (ReCiMe); ver, entre outras publicações da Rede, Sposito, Elias e Soares (2010) e o site http://www.recime.org.

${ }^{5}$ Ao tratar da diferenciação socioespacial, na escala da rede urbana, Corrêa assegura que "[...] manifesta-se por intermédio da diferenciação funcional dos centros urbanos, assim como em termos de tamanho de cidades [...]. Lugares centrais hierarquizados e centros especializados, ou uma combinação de ambos, descrevem a diferenciação sócio-espacial na escala da rede urbana. Essa diferenciação associa-se, em parte, às características diferenciadas do mundo agro-pastoril no que tange à estrutura agrária, ao habitat rural e ao processo produtivo aí incluindo-se a pauta dos produtos." (2007b, p.64). Ainda para o autor, cada centro urbano situa-se simultaneamente em pelo menos duas redes: uma constituída por localidades centrais, na qual cada centro tem uma posição; "[...] e outra, menos sistemática e mais irregular, na qual cada centro desempenha um papel singular e/ou complementar a outros centros [...]" (CORRÊA 1996, p.100).
}

Estudos Geográficos, Rio Claro, 15(1): 62-87, jan./jun. 2017 (ISSN 1678_698X)

http://www.periodicos.rc.biblioteca.unesp.br/index.php/estgeo 
[...] sempre esteve associada à definição de seus papéis regionais e ao potencial de comunicação e articulação proporcionado por suas situações geográficas, tendo o consumo um papel mais importante que a produção na estruturação dos fluxos que definem o papel intermediário dessas cidades. (2001, p.635-6).

Nesse sentido, numa leitura desse processo de especialização funcional, Calixto, afirma:

Localizada em uma região onde a agricultura baseada em significativo conteúdo de técnica, ciência e informação predomina como principal atividade econômica, a cidade desenvolve-se a partir das relações de trabalho e de produção, calcadas na necessidade de equipamentos e serviços demandados pela produção agrícola regional. Pensando que as cidades de menor porte (ainda que não ligadas exclusivamente de modo hierárquico) são capazes de atender apenas às necessidades/exigências de menor nível de especialização, fica a cargo de Dourados a oferta de produtos e tecnologia mais avançados, produtos oriundos do comércio mais sofisticado, assim como de serviços urbanos mais especializados. (2011, p.03).

Ainda em relação aos papéis regionais, Silva (2010, p.81), em específico sobre os serviços de saúde, entende que "... reforçam o papel de centralidade de Dourados, pois cerca de $60 \%$ dos atendimentos realizados somente nos hospitais são de usuários de outros municípios, que se deslocam, diariamente ou mensalmente, de acordo com o serviço buscado (que varia desde consultas de rotina a tratamentos mais especializados)."

A mesma autora também aponta que, no que diz respeito ao ensino superior, "[...] a centralidade de Dourados é ainda mais expressiva, haja vista a ampliação de sua influência para além dos limites do Estado [...]" (SILVA, 2010, p.118).

Feitas tais considerações sobre a condição regional de Dourados, a seguir, apresentam-se dados que demonstram o seu papel diferenciado na oferta do ensino superior, contribuindo para assegurar e reforçar sua centralidade.

\section{A OFERTA DO ENSINO SUPERIOR NA REDE URBANA DE DOURADOS}

Quando se considera a rede urbana de DouradosErro! Fonte de referência não encontrada., Ponta Porã é o município em que se verifica a presença de maior número de instituições de ensino superior (IES) - 07 no total. Em seguida, estão Dourados (05 IES) e Naviraí (04 IES) - Tabela 01.

Se a questão é analisada apenas por esse dado (quantidade de IES), o papel exercido por Dourados poderia tornar-se questionável, já que não possui o maior número de instituições de ensino superior. No entanto, torna-se necessário acrescer outros elementos como, por exemplo, aqueles ligados à concentração da oferta de cursos, uma vez que o número de instituições, por si só, não revela o tamanho e a complexidade das instituições em questão e, consequentemente, não revela os fluxos estabelecidos a partir da oferta do ensino superior. 
Tabela 01. Presença de unidades acadêmicas de IES (modalidade presencial) na rede urbana de Dourados-MS (2015)

\begin{tabular}{lrrrr}
\hline \multicolumn{4}{c}{ Rede urbana de Dourados-MS } \\
\hline Município & IES Pública & IES Privada & \multicolumn{1}{c}{ Total } \\
\hline Amambai & 1 & 1 & 2 \\
Caarapó & 0 & 1 & 1 \\
Dourados & 2 & 3 & 5 \\
Fátima do Sul & 0 & 1 & 1 \\
Glória de Dourados & 1 & 0 & 1 \\
Guaíra/PR & 0 & 1 & 1 \\
Ivinhema & 1 & 0 & 1 \\
Maracaju & 1 & 0 & 1 \\
Mundo Novo & 1 & 0 & 1 \\
Naviraí & 2 & 2 & 4 \\
Ponta Porã & 3 & 4 & 7 \\
\hline Total & 12 & 13 & 25 \\
& $48,00 \%$ & $52,00 \%$ & $100,00 \%$ \\
\hline
\end{tabular}

${ }^{1}$ Foram consideradas para análise as unidades dos Institutos Federais que no estado de MS recebem a nomenclatura IFMS - Instituto Federal de Mato Grosso do Sul.

Fonte: e-MEC, acesso em agosto de 2015

Na rede urbana de Dourados, o número de instituições do setor público (12) é próximo ao do setor privado (13 IES) - ver Tabela 01. O "equilíbrio" é garantido, principalmente, pela presença da Universidade Estadual de Mato Grosso do Sul (UEMS).

A UEMS possui unidades acadêmicas nos municípios de Glória de Dourados (9.997 habitantes), Ivinhema (22.341 habitantes), Maracaju (37.405 habitantes) e Mundo Novo (17.043 habitantes), onde não há instituições privadas. ${ }^{6}$ No caso de 04 municípios (Glória de Dourados, Ivinhema, Maracaju e Mundo Novo), o que se percebe é a ausência de instituições privadas. O contrário é verificado em Caarapó e em Fátima do Sul, onde não há instituição pública. As instituições públicas estão presentes em 08 municípios, dos 11 que possuem ao menos uma instituição.

Já em relação às instituições privadas, que estão em 07 municípios, o maior número está em Ponta Porã (04 IES), Dourados (03 IES) e em Naviraí (02 IES). Esse dado revela a opção dos agentes das instituições do setor privado, em concentrar as atividades em centros que apresentam maior complexidade e, nesse caso, maior tamanho demográfico também.

Em relação à oferta, os municípios da rede urbana de Dourados contam com 152 cursos de graduação. Possuem papel de destaque, além de Dourados (87 cursos $-57,23 \%$ da oferta de toda a rede urbana), Ponta Porã, com 26 cursos, Naviraí com 13 cursos e Guaíra com 07 cursos - ver Tabela 02.

É importante destacar, a partir dos dados da Tabela 02, a oferta de ensino superior em centros da rede urbana de Dourados que estão em níveis de centralidade diferente da classificação de Centro Local (último nível considerado). As instituições que se inserem nesses centros, além de atender a população do município, passam a atender também centros de diferentes portes, sobretudo os menores e que mantêm relações mais diretas.

\footnotetext{
${ }^{6}$ Três desses centros são classificados como Centro Local (IBGE/Regic, 2008) - Glória de Dourados, Ivinhema e Maracaju.

Estudos Geográficos, Rio Claro, 15(1): 62-87, jan./jun. 2017 (ISSN 1678—698X)

http://www.periodicos.rc.biblioteca.unesp.br/index.php/estgeo 
Tabela 02. Oferta de cursos de graduação (modalidade presencial) na rede urbana de Dourados-MS (2015)

\begin{tabular}{lrr}
\hline \multicolumn{3}{c}{ Rede urbana de Dourados-MS } \\
\hline Município & $\begin{array}{c}\text { Quantidade } \\
\text { de Cursos }\end{array}$ & \multicolumn{1}{c}{$\%$} \\
\hline Amambai & 5 & $3,29 \%$ \\
Caarapó & 2 & $1,32 \%$ \\
Dourados & $\mathbf{8 7}$ & $\mathbf{5 7 , 2 4 \%}$ \\
Fátima do Sul & 4 & $2,63 \%$ \\
Glória de Dourados & 2 & $1,32 \%$ \\
Guaíra/PR & 7 & $4,61 \%$ \\
Ivinhema & 2 & $1,32 \%$ \\
Maracaju & 2 & $1,32 \%$ \\
Mundo Novo & 2 & $1,32 \%$ \\
Naviraí & 13 & $8,55 \%$ \\
Ponta Porã & 26 & $17,11 \%$ \\
Total & 152 & $100,00 \%$ \\
\hline
\end{tabular}

Fonte: e-MEC, acesso em agosto de 2015

Tratando-se especificamente da quantidade de instituições e de cursos (Quadro 01), as cidades de Ponta Porã e de Naviraí têm reafirmado seu papel de destaque na rede. Ponta Porã possui maior número de instituições do que Dourados, e isso sem considerar as instituições paraguaias, localizadas na cidade gêmea Pedro Juan Caballero (PY) que, ainda que não seja nosso propósito analisar, introduz novo elemento à análise. Enquanto Ponta Porã possui 07 instituições (26 cursos), Naviraí possui 04 (13 cursos). Já em relação à quantidade de vagas, em Ponta Porã há a oferta de 1.670 e, em Naviraí, 903.

Fátima do Sul aparece com uma expressiva oferta de vagas (640), concentrada em uma única instituição que, para os cursos de Educação Física (Licenciatura e Bacharelado) oferta 400 vagas; para o curso de Enfermagem, 40 vagas e, para o curso de Pedagogia, 200 vagas.

Esses dados demonstram a necessidade de relativizar a dimensão dessa oferta, uma vez que Fátima de Sul e Dourados estão bem próximos (cerca de 30 $\mathrm{km}$ ), o que condiciona a intensificação da relação entre elas e o que pode resultar numa "coerção" dessa oferta em Fátima do Sul já que, em Dourados, também há oferta dos cursos de Educação Física (490 vagas) e de Pedagogia (190 vagas) em três instituições (UEMS, UFGD e UNIGRAN), duas delas públicas. Por outro lado, o que pode existir também é, ao contrário do que se convencionou, o fluxo de alunos de Dourados em direção a Fátima do Sul ${ }^{7}$.

Ainda em relação ao número de vagas, Guaíra, apesar de também possuir apenas uma instituição (setor privado) para a oferta de 07 cursos, concentra 585 vagas. Já Amambai, apesar de contar com duas instituições (uma delas pública) para a oferta de 05 cursos, disponibiliza 380 vagas. Esses centros possuem papéis diferenciados no que diz respeito ao ensino superior e, embora em níveis de centralidade estejam na mesma condição (Centro de Zona B), as diferenciações socioespaciais acabam imprimindo a diferenciação.

\footnotetext{
${ }^{7}$ O município de Fátima do Sul possui 19.035 habitantes, dentre os quais $2.161(11,35 \%)$ possuem entre 18 e 24 anos de idade. O total de pessoas que frequentam o ensino superior no município é de $715(3,76 \%)$. Estudos Geográficos, Rio Claro, 15(1): 62-87, jan./jun. 2017 (ISSN 1678-698X) 
Quadro 01.Número de instituições e cursos de graduação (modalidade presencial) na rede urbana de Dourados-MS (2015) Fonte: site das instituições; e-MEC, acesso em agosto de 2015

\begin{tabular}{|c|c|c|c|c|c|c|c|c|c|}
\hline Centro urbano & Instituição & \begin{tabular}{|r} 
Cursos \\
\end{tabular} & Vagas & Grau & Centro urbano & Instituição & $\begin{array}{r}\text { Cursos } \\
\end{array}$ & Vagas & Grau \\
\hline \multirow{6}{*}{ Amambai } & HEMS $^{1}$ & Ciências Sociais & 40 & Lic & \multirow{3}{*}{ Ivinhema } & \multirow{2}{*}{ UEMS $^{1}$} & Ciências Biológicas & 15 & Bach \\
\hline & & \begin{tabular}{|l} 
História \\
\end{tabular} & 40 & Lic & & & Ciências Biológicas & 35 & \\
\hline & \multirow{3}{*}{ FIAMA $^{2}$} & Administração & 100 & Bach & & & Leticlas biviugieds & \multicolumn{2}{|l|}{50} \\
\hline & & Ciências Contábeis & 100 & Bach & \multirow{3}{*}{ Maracaju } & \multirow{2}{*}{ UEMS $^{1}$} & Administração & \multicolumn{2}{|r|}{ Bach } \\
\hline & & \begin{tabular}{|l|l|} 
Pedagogia \\
\end{tabular} & 100 & Lic & & & \begin{tabular}{|l|} 
Pedagogia \\
\end{tabular} & 40 & Lic \\
\hline & & Total & 380 & & & & Total & \multicolumn{2}{|l|}{80} \\
\hline \multirow{3}{*}{ Caarapó } & \multirow{3}{*}{ FETAC $^{3}$} & Administração & 50 & Bach & \multirow{3}{*}{ Mundo Novo } & \multirow{3}{*}{ UEMS $^{1}$} & \multirow{3}{*}{\begin{tabular}{|l|} 
Ciências Biológicas \\
Tecnologia em Gestão Ambiental \\
Total
\end{tabular}} & 40 & Lic \\
\hline & & Ciências Contábeis & 50 & Bach & & & & \multirow{2}{*}{\multicolumn{2}{|c|}{\begin{tabular}{|l|}
40 \\
80
\end{tabular}}} \\
\hline & & Total & 100 & & & & & & \\
\hline \multirow{5}{*}{ Fátima do Sul } & \multirow{5}{*}{ FAFS $^{4}$} & \begin{tabular}{|l} 
Educação Física \\
\end{tabular} & 200 & Bach & & \multirow{5}{*}{ FAP $^{9}$} & Administração & 100 & Bach \\
\hline & & Educação Física & 200 & Lic & & & Ciências Contábeis & 60 & Bach \\
\hline & & \begin{tabular}{|l} 
Enfermagem \\
\end{tabular} & 40 & Bach & & & Geografia & 60 & Lic \\
\hline & & \begin{tabular}{|l|} 
Pedagogia \\
\end{tabular} & 200 & Lic & & & \begin{tabular}{|l|} 
História \\
\end{tabular} & 60 & Lic \\
\hline & & Total & 640 & & & & Letras - Espanhol e respc. Literat. & 100 & Lic \\
\hline \multirow{3}{*}{ Glória de Dourados } & \multirow{3}{*}{ UEMS $^{1}$} & Agroecologia & 50 & Tec & & \multirow{6}{*}{ FAMAG $^{10}$} & \begin{tabular}{|l|} 
Artes Visuais \\
\end{tabular} & 40 & Lic \\
\hline & & Produção Sucroalcooleira & 50 & Tec & & & Ciências Biológicas & 60 & Lic \\
\hline & & Total & 100 & & & & Ciências Contábeis & 80 & Bach \\
\hline & & Administração & 96 & Lic & & & Educação Física & 80 & Lic \\
\hline & & Análise e Des. de Sistemas & 83 & Tec & & & Estética e Cosmetologia & 50 & Tec \\
\hline & & Estética e Cosmética & 80 & Tec & & & \begin{tabular}{|l|} 
Pedagogia \\
\end{tabular} & 80 & Lic \\
\hline Cuńŕ & UNIPAR $^{5}$ & Gestão Ambiental & 80 & Tec & & & Ciência da Computação & 50 & Bach \\
\hline Guaíra & & \begin{tabular}{|l} 
Direito \\
\end{tabular} & 97 & Bach & & & Engenharia Mecatrônica & 50 & Bach \\
\hline & & \begin{tabular}{|l|} 
Enfermagem \\
\end{tabular} & 65 & Bach & Ponta Porã & UFMS $^{6}$ & \begin{tabular}{|l|} 
Matemática \\
\end{tabular} & 40 & Lic \\
\hline & & \begin{tabular}{|l|} 
Pedagogia \\
\end{tabular} & 84 & Lic & & & \begin{tabular}{|l} 
Pedagogia \\
\end{tabular} & 40 & Lic \\
\hline & & Total & 585 & & & & Sistemas de Informação & 50 & Bach \\
\hline & $\mathrm{UFMS}^{6}$ & Arquitetura e Urbanismo & 50 & Bach & & 15Mc11 11 & Agronegócio & 80 & Tec \\
\hline & & Ciências Sociais & 60 & Lic & & IFMS & Agronomia & 40 & Bach \\
\hline & & Pedagogia & 60 & Lic & & & Administração & 60 & Bach \\
\hline & FACINAV $^{\prime}$ & Ciências Contábeis & 60 & Bach & & $\mathrm{EJP}^{12} \mathrm{Y}$ & Ciência da Computação & 80 & Bach \\
\hline & & Administração & 100 & Bach & & & Direito & 80 & Bach \\
\hline & EINAY 8 & Geografia & 93 & Lic & & & Letras - Português e Espanhol & 80 & Lic \\
\hline & FINAV ${ }^{\circ}$ & Letras - Inglês & 100 & Lic & & & Administração & 50 & Bach \\
\hline Naviraí & & \begin{tabular}{|l} 
Pedagogia \\
\end{tabular} & 150 & Lic & & UEMS $^{1}$ & Ciências Contábeis & 50 & \begin{tabular}{|l|l|} 
Bach \\
\end{tabular} \\
\hline & & Tecnologia em Alimentos & 50 & Tec & & & Ciências Econômicas & 50 & \begin{tabular}{|l|l|} 
Bach \\
\end{tabular} \\
\hline & & Engenharia de Alimentos & 50 & Bach & & FATEP $^{13}$ & \begin{tabular}{|l} 
Engenharia Civil \\
\end{tabular} & 100 & Bach \\
\hline & UEMS $^{1}$ & Direito & 50 & Bach & & & Total & 1.670 & \\
\hline & & \begin{tabular}{|l|} 
Matemática \\
\end{tabular} & 30 & Lic & & & & & \\
\hline & & Química & 50 & Lic & & & Total de vagas & 4.588 & \\
\hline & & $\overline{\text { Total }}$ & 903 & & & & & & \\
\hline
\end{tabular}

Universidade Estadual de Mato Grosso do Sul (UEMS), ${ }^{2}$ Faculdade de Amambai (FIAMA), ${ }^{3}$ Faculdade de Educação, Tecnologia e Administração de Caarapó (FETAC), ${ }^{4}$ Faculdade de Administração de Fátima do Sul (FAFS), ${ }^{5}$ Universidade Paranaense (UNIPAR), ${ }^{6}$ Universidade Federal de Mato Grosso do Sul (UFMS), Faculdade de Ciências Contábeis de Naviraí (FACINAV), ${ }^{\circ}$ Faculdades Integradas de Naviraí (FINAV), ${ }^{9}$ Faculdade de Ponta Porã (FAP), ${ }^{1}$ Faculdades Magsul
(FAMAG), ${ }^{11}$ Instituto Federal de Mato Grosso do Sul (IFMS) e ${ }^{12}$ Faculdades Integradas de Ponta Porã (FIP). ${ }^{13}$ Faculdade de Tecnologia de Ponta Porã (FATEP).

Estudos Geográficos, Rio Claro, 15(1): 62-87, jan./jun. 2017 (ISSN 1678-698X)

http://www.periodicos.rc.biblioteca.unesp.br/index.php/estgeo 
Nesse sentido, enquanto Amambai possui 34.730 habitantes - dentre os quais 22.375 (64,43\%) residem na cidade (IBGE, 2010) -, Guaíra possui 30.704 habitantes, destes $28.206(91,86 \%)$ residem na cidade (IBGE, 2010). Enquanto a primeira dista, aproximadamente, $130 \mathrm{~km}$ de Dourados e se vincula diretamente, a segunda está a $266 \mathrm{~km}$ de distância, vinculando-se indiretamente (por intermédio de Mundo Novo, um Centro Sub-Regional A).

Por outro lado, Guaíra vincula-se diretamente a Umuarama - PR, Centro SubRegional A (subordinado diretamente a Curitiba - PR), que está a uma distância de, aproximadamente, $120 \mathrm{~km}$. Guaíra ainda mantém proximidade com Cascavel (cerca de $150 \mathrm{~km}$ ) e com Maringá (cerca de $248 \mathrm{~km}$ ), o que poderia relativizar a ligação com Dourados que, além de mais distante, em nível de centralidade, mostra-se em uma condição inferior àqueles - Cascavel e Maringá se enquadram como Capital Regional B. Ainda nessa perspectiva, apesar de Mundo Novo subordinar Guaíra, sua expressão na rede urbana em relação ao ensino superior é pequena, concentra 80 vagas em dois cursos de graduação em uma única instituição.

Dentre os cursos listados, apenas o curso de graduação em Engenharia Mecatrônica (UFMS/Ponta Porã) não é ofertado em Dourados. O que diferencia os centros que se vinculam a Dourados são os cursos do grau tecnológico que são ofertados em Glória de Dourados (Agroecologia e Produção Sucroalcooleira), Ivinhema (Agroecologia e Produção Sucroalcooleira), Mundo Novo (Gestão Ambiental), Naviraí (Tecnologia em Alimentos) e em Ponta Porã (Agronegócio) - o que pode ser observado a partir da comparação entre o Quadro 01 e o Quadro 02.

A expressividade de Dourados em relação à oferta de cursos de graduação pode ser mais bem apreendida a partir do Quadro 02, em que está demonstrada a oferta de cada instituição. A UFGD e a UNIGRAN são as instituições que mais possuem cursos de graduação, 33 e 28, respectivamente.

As instituições públicas (UEMS e UFGD), diferentemente das demais, não ofertam cursos para o grau tecnológico. Já quando se observa o número de vagas ofertadas, fica perceptível a superioridade das IES do segmento privado. A UNIGRAN, sozinha, oferta 4.740 vagas, número superior às ofertas das duas instituições públicas juntas (UFGD e UEMS, 1.925 e 650 vagas, respectivamente).

Anualmente são ofertadas 9.315 vagas nos cursos de graduação, sendo que $72,36 \%$ desse total de vagas é de responsabilidade do setor privado. A UNIGRAN e a $F A D$, as duas instituições com maior oferta do setor privado, travam concorrência principalmente nas áreas da ciência vinculada, mais diretamente, às atividades agropecuárias, justamente pelas demandas de trabalho requeridas num campo modernizado, cada vez mais cientifizado e que encontra, na cidade média, "[...] muitas respostas às suas exigências em ciência, técnica e informação, incluindo uma demanda importante de bens e serviços técnicos e científicos [...]" (SANTOS e SILVEIRA, 2011, p.281). Ainda para os autores,

[...] as cidades médias têm como papel o suprimento imediato e próximo da informação requerida pelas atividades agrícolas e desse modo constituem em intérpretes da técnica e do mundo. Em muitos casos, a atividade urbana acaba sendo claramente especializada, graças às suas relações próximas e necessárias com a produção regional [...] (2011, p.281).

Nesse sentido, a oferta dos cursos de graduação passa a ser influenciada pela atividade produtiva regional, ao passo que as instituições de ensino superior, Estudos Geográficos, Rio Claro, 15(1): 62-87, jan./jun. 2017 (ISSN 1678-698X) 
em resposta aos estímulos dessas atividades, tornam-se responsáveis pela formação de mão de obra qualificada ao atendimento, mesmo que não exclusivamente, de demandas criadas no campo.

\section{Quadro 02. Cursos de Graduação modalidade presencial em Dourados-MS (2015)}

\begin{tabular}{|c|c|c|c|c|c|}
\hline \multicolumn{3}{|l|}{ FAD $^{\top}$} & \multicolumn{3}{|l|}{ UEMS $^{4}$} \\
\hline Curso & Vagas & Grau & Curso & Vagas & Grau \\
\hline Administração & 700 & Bach & Ciência da Computação & 50 & Bach \\
\hline Agronomia & 110 & Bach & Ciências Biológicas & 50 & Lic \\
\hline Ciências Contábeis & 150 & Bach & Direito & 50 & Bach \\
\hline Comunicação Social & 150 & Bach & Enfermagem & 50 & Bach \\
\hline Gestão de Recursos Humanos & 140 & Tec & Engenharia Ambiental & 50 & Bach \\
\hline Gestão Financeira & 100 & Tec & Engenharia Física & 50 & Bach \\
\hline Logística & 100 & Tec & Física & 40 & Lic \\
\hline Medicina Veterinária & 180 & Bach & Letras & 80 & Lic \\
\hline Produção Multimídia & 100 & Tec & Matemática & 40 & Lic \\
\hline Psicologia & 100 & Bach & Pedagogia & 40 & Lic \\
\hline Relações Internacionais & 120 & Bach & Química & 40 & Lic \\
\hline Total & & 1.950 & Química Industrial & 30 & Bach \\
\hline \multicolumn{3}{|l|}{ UNIGRAN $^{2}$} & Sistemas de Informação & 40 & Bach \\
\hline Administração & 180 & Bach & Turismo & 40 & Bach \\
\hline Agronomia & 140 & Bach & Total & & 650 \\
\hline Arquitetura e Urbanismo & 120 & Bach & \multicolumn{3}{|l|}{ UFGD $^{5}$} \\
\hline Artes Visuais & 60 & Lic & Administração & 50 & Bach \\
\hline Biomedicina & 80 & Bach & Agronomia & 50 & Bach \\
\hline Ciência da Computação & 100 & Bach & Artes Cênicas & 60 & Bach e Lic \\
\hline Ciências Biológicas & 140 & Bach e Lic & Biotecnologia & 55 & Bach \\
\hline Ciências Contábeis & 160 & Bach & Ciências Biológicas & 60 & Bach e Lic \\
\hline Comunicação Social & 60 & Bach & Ciências Contábeis & 50 & Bach \\
\hline Design de Interiores & 100 & Tec & Ciências Econômicas & 50 & Bach \\
\hline Direito & 480 & Bach & Ciências Sociais & 60 & Bach e Lic \\
\hline Educação Física & 440 & Bach e Lic & Direito & 55 & Bach \\
\hline Enfermagem & 240 & Bach & Educação do Campo & 120 & Lic \\
\hline Engenharia Civil & 250 & Bach & Educação Física & 50 & Lic \\
\hline Engenharia Mecânica & 120 & Bach & Engenharia Civil & 60 & Bach \\
\hline Estética e Cosmética & 260 & Bach & Engenharia Agrícola & 50 & Bach \\
\hline Farmácia & 320 & Bach & Engenharia de Alimentos & 51 & Bach \\
\hline Fisioterapia & 120 & Bach & Engenharia de Aquicultura & 60 & Bach \\
\hline Jornalismo & 60 & Bach & Engenharia de Computação & 60 & Bach \\
\hline Medicina Veterinária & 160 & Bach & Engenharia de Energia & 51 & Bach \\
\hline Nutrição & 120 & Bach & Engenharia de Produção & 52 & Bach \\
\hline Odontologia & 90 & Bach & Engenharia Mecânica & 60 & Bach \\
\hline Pedagogia & 100 & Lic & Geografia & 70 & Bach e Lic \\
\hline Produção Agrícola & 160 & Tec & Gestão Ambiental & 50 & Bach \\
\hline Produção Publicitária & 80 & Tec & História & 70 & Bach e Lic \\
\hline Psicologia & 360 & Bach e Lic & Letras & 70 & Lic \\
\hline Radiologia & 160 & Tec & Lic Intercultural Indígena & 60 & Lic \\
\hline Serviço Social & 80 & Bach & Matemática & 51 & Lic \\
\hline Total & \multicolumn{2}{|r|}{4.740} & Medicina & 80 & Bach \\
\hline \multicolumn{3}{|l|}{ FTAW $^{3}$} & Nutrição & 50 & Bach \\
\hline Teologia & 50 & Bach & Pedagogia & 50 & Lic \\
\hline Total & & 50 & Psicologia & 60 & Bach e Lic \\
\hline \multirow{5}{*}{ Total de Vagas } & \multirow{5}{*}{\multicolumn{2}{|c|}{9.315}} & Química & 54 & Bach e Lic \\
\hline & & & Relações Internacionais & 55 & Bach \\
\hline & & & Sistemas de Informação & 51 & Bach \\
\hline & & & Zootecnia & 50 & Bach \\
\hline & & & Total & \multicolumn{2}{|r|}{1.925} \\
\hline
\end{tabular}

${ }^{1}$ Faculdade Anhanguera de Dourados (FAD). ${ }^{2}$ Centro Universitário da Grande Dourados (unigran). ${ }^{3}$ Faculdade Teológica e Seminário Batista Ana Wollerman (FTWA). ${ }^{4}$ Universidade Estadual de Mato Grosso do Sul (UEMS). ${ }^{5}$ Universidade Federal da Grande Dourados (UFGD).

Fonte: sites das instituições, e-MEC, acesso em agosto de 2015

Estudos Geográficos, Rio Claro, 15(1): 62-87, jan./jun. 2017 (ISSN 1678—698X)

http://www.periodicos.rc.biblioteca.unesp.br/index.php/estgeo 
Essas demandas são expressas não só na oferta de cursos de graduação e na oferta de cursos tecnológicos vinculados à atividade produtiva, mas na quantidade de vagas ofertadas. Ao que parece, apesar da concorrência, as duas instituições privadas têm conquistado mercado, uma vez que a UNIGRAN disponibiliza 140 vagas para o curso de Agronomia $^{8}$ e 160 para o de Medicina Veterinária, enquanto que a FAD oferece 110 vagas para o curso de Agronomia e 180 vagas para Medicina Veterinária.

Esses números explicitam que a oferta de vagas é baseada em demandas cada vez mais referenciadas na escala regional. Proporcional e economicamente, não é viável pensar na oferta e no preenchimento de 310 vagas para o curso de Agronomia (UFGD, FAD e UNIGRAN) e 340 vagas para o curso de Medicina Veterinária (FAD e UNIGRAN), se forem consideradas apenas as demandas locais. Nesse sentido, ao mesmo tempo em que se configura em Dourados uma condição diferenciada de oferta do ensino superior, se comparado aos outros centros da rede urbana regional, essa oferta (expressa na quantidade de cursos e de vagas) está atrelada às demandas regionais, questão que será explorada adiante.

\section{A REDE URBANA E A OFERTA DE ENSINO SUPERIOR}

Neste item serão analisados os dados da origem dos discentes dos cursos de graduação, na modalidade presencial, que têm vínculos com as instituições de Dourados, ou seja, serão quantificados os alunos de outros municípios que vêm estudar nesse centro regional.

Quando considerados os ingressos na UNIGRAN (Centro Universitário da Grande Dourados), por exemplo, a partir de sua avaliação institucional, constata-se que de um total de 2.081, 41,90\% já moravam em Dourados antes de ingressar na instituição - ver Tabela 03 . Apesar de cerca de 30\% dos discentes não terem respondido ${ }^{9}$ essa questão, é expressivo o número dos que ingressaram na UNIGRAN e que não eram de Dourados - 27,15\%. Dentre esses, $20,76 \%$ mudaramse para Dourados, especificamente, em função do ingresso na instituição. Essa condição revela um importante dado: a mobilidade para Dourados, para ter acesso ao ensino superior, o que acaba exigindo do discente condição financeira para arcar, minimamente, com as despesas com moradia e alimentação. Essa questão traz uma contribuição ímpar à análise que se pretende realizar, já que mais de 430 alunos se mudaram para Dourados, no período analisado, por vincularem-se à UNIGRAN.

Portanto, esse público contribui diretamente com a economia da cidade fomentando, principalmente, o setor imobiliário que, ao perceber nessa demanda uma possibilidade de ampliação de lucro, passa a investir na construção de edificações para locação pelo público universitário ${ }^{10}$.

\footnotetext{
${ }^{8}$ Somadas às vagas disponibilizadas pela UFGD, chega a 300 o número de vagas ofertadas para esse curso.

${ }^{9}$ Um indicativo para que esse número seja elevado, como apresentado, é a ausência de alternativas para aqueles discentes que não se enquadram nas condições dispostas, ou seja, para aqueles que não residem em Dourados.

${ }^{10}$ É válido salientar que essa demanda exposta se refere a apenas uma instituição; assim, a tendência é que ela se revele mais ampla.

Estudos Geográficos, Rio Claro, 15(1): 62-87, jan./jun. 2017 (ISSN 1678-698X)
}

http://www.periodicos.rc.biblioteca.unesp.br/index.php/estgeo 
Tabela 03. Origem dos calouros dos cursos de graduação presencial da UNIGRAN (2011)

\begin{tabular}{|c|c|c|}
\hline \multirow{2}{*}{ Condição } & \multicolumn{2}{|c|}{ Calouros } \\
\hline & № & $\%$ \\
\hline $\begin{array}{l}\text { Já morava em Dourados antes de ingressar na } \\
\text { UNIGRAN }\end{array}$ & 872 & $41,90 \%$ \\
\hline $\begin{array}{l}\text { Se mudou para Dourados em função de seu } \\
\text { ingresso na UNIGRAN }\end{array}$ & 432 & $20,76 \%$ \\
\hline $\begin{array}{l}\text { Se mudou para Dourados por outros motivos e, } \\
\text { posteriormente, ingressou na UNIGRAN }\end{array}$ & 133 & $6,39 \%$ \\
\hline Não responderam & 644 & $30,95 \%$ \\
\hline Total & 2.081 & $100 \%$ \\
\hline
\end{tabular}

Fonte: UNIGRAN (2011)

Ainda em relação aos discentes da UNIGRAN, é possível comparar a tabela anterior com a Tabela $04 \mathrm{em}$ que, diferentemente da primeira, a quantidade de discentes que não responderam à questão proposta foi mínima $(0,67 \%$ para os calouros e $0,81 \%$ para os veteranos). Dentre os calouros (2.081 discentes), 1.384 , ou $66,51 \%$, responderam que moram na cidade de Dourados, o que contrasta com os 1.437 que responderam que moram em Dourados - essa diferença pode ser uma indicação de que parcela desses alunos reside no campo e, por isso, não constam no estrato que informou morar na cidade de Dourados da Tabela 04.

Tabela 04. Local de residência dos discentes dos cursos de graduação da UNIGRAN (2011)

\begin{tabular}{l|r|r|r|r|r|r}
\hline \multirow{2}{*}{ Local } & \multicolumn{2}{|c|}{ Calouros } & \multicolumn{2}{c|}{ Veteranos } & \multicolumn{2}{c}{ Total } \\
\cline { 2 - 7 } & \multicolumn{1}{|c}{ № } & \multicolumn{1}{c}{$\%$} & \multicolumn{1}{c}{ № } & \multicolumn{1}{c}{$\%$} & \multicolumn{1}{c}{ № } & \multicolumn{1}{c}{$\%$} \\
\hline Cidade de Dourados & 1.384 & $66,51 \%$ & 2.113 & $65,54 \%$ & 3.497 & $65,92 \%$ \\
Região da Grande Dourados & 270 & $12,97 \%$ & 479 & $14,86 \%$ & 749 & $14,12 \%$ \\
Campo Grande & 5 & $0,24 \%$ & 20 & $0,62 \%$ & 25 & $0,47 \%$ \\
Outras & 408 & $19,61 \%$ & 586 & $18,18 \%$ & 994 & $18,74 \%$ \\
Não responderam & 14 & $0,67 \%$ & 26 & $0,81 \%$ & 40 & $0,75 \%$ \\
Total & 2.081 & $100 \%$ & 3.224 & $100 \%$ & 5.305 & $100 \%$ \\
\hline
\end{tabular}

Fonte: UNIGRAN (2011)

Ainda em relação à Tabela $04,14,12 \%$ dos discentes responderam que moram na "Região da Grande Dourados", enquanto que $18,74 \%$ responderam que moram em outros locais. Como não se sabe o que a instituição considera por Região da Grande Dourados, não se pode apurar, mais especificamente, a área abrangida por essa informação. Como já foi abordado em outro momento ${ }^{11}$, instituições, órgãos governamentais e de representação de classe, além de empresas locais, ao utilizarem-se do recorte "Região da Grande Dourados" fazem com que essa "regionalização" vá ganhando delimitações particulares. Assim, dificulta-se o entendimento do que seria a "Região da Grande Dourados" que, há algum tempo, deixou de ser aquela proposição realizada inicialmente pelo Programa Especial de Desenvolvimento da Grande Dourados - PRODEGRAN.

\footnotetext{
${ }^{11} \mathrm{~A}$ respeito da(s) delimitação(ões) da Região da Grande Dourados, indica-se a leitura de Moreno (2012). Estudos Geográficos, Rio Claro, 15(1): 62-87, jan./jun. 2017 (ISSN 1678—698X) 
Nesse sentido, surge uma problemática de delimitação que se reflete em questões de como os municípios são inseridos e/ou excluídos dessa "regionalização" e de como a população se percebe pertencente ou não a essa "unidade". Essa problemática tem desdobramentos entre os discentes que responderem ao questionário, pois se a instituição entende a "Região da Grande Dourados" como sendo a área próxima de Dourados, com distâncias que permitam o fluxo de discentes, em um intervalo de tempo que seja razoável ${ }^{12}$, o estrato que tem essa área como origem deveria revelar-se superior, e não o contrário. Portanto, por não se saber, ao certo, a área ou os municípios a que essas alternativas do questionário se referem, a análise fica comprometida.

O importante, nesse sentido, é reforçar que 1.768 discentes, ou 33,33\% dos discentes que participaram da avaliação institucional, não residem em Dourados, portanto esse percentual reforça a ideia de que a escala regional influencia na formação das turmas dos cursos de graduação, o que influencia, também, na definição de vagas nos vestibulares da instituição.

Por outro lado, outras questões da avaliação institucional contribuem para a quantificação dos fluxos de alunos na rede urbana de Dourados como, por exemplo, os meios de locomoção utilizados pelos discentes para ir à UNIGRAN. Entre os calouros, $32,34 \%$ e $30,33 \%$, entre os veteranos ${ }^{13}$, responderam que utilizam ônibus escolar (transporte interurbano) como meio de locomoção. A média dos discentes que se utiliza desse meio de locomoção, portanto, é de $31,12 \%$.

A partir dos dados referentes aos meios de locomoção, a participação da região na formação do público discente da UNIGRAN fica mais clara. A quantidade de discentes que se utiliza dessa forma de transporte $(31,12 \%$ ou 1.651 alunos) é semelhante àquela que tem como origem a área de influência da instituição, ou a área cuja distância, tanto os alunos como as empresas de transportes estão dispostos a percorrer até Dourados.

Já na UFGD ${ }^{14}$, a representatividade da rede urbana de Dourados, em relação ao local de residência, é de $18,40 \%$, isso quando não se considerar Dourados que, sozinho, representa $67,47 \%$ do local de residência dos discentes dessa instituição ver Tabela 05.

Os municípios mais representativos são Ponta Porã, Fátima do Sul, Itaporã, Amambai e Caarapó, que foram informados como sendo local de residência de, respectivamente, $2,69 \%, 2,40 \%, 1,96 \%, 1,76 \%$ e $1,74 \%$ do total de discentes da instituição.

Ponta Porã, que se distancia de Dourados cerca de $120 \mathrm{~km}$, apesar de possuir 07 instituições de ensino superior, tem a participação mais representativa. Mesmo se tratando da escala da rede urbana, as distâncias influenciam, de maneira decisiva, dentre outros elementos, na intensidade dos fluxos de discentes, já que o tamanho demográfico não é o único determinante na formação do público das instituições. Assim, tem-se a participação dos municípios de Fátima do Sul, Itaporã, Caarapó e Rio Brilhante que, apesar de não serem os mais representativos em

\footnotetext{
${ }^{12}$ Vale destacar que o tempo de viagem entre as cidades da rede urbana e Dourados, de onde partem ônibus diariamente, considerando aquelas mais distantes (Amambai e Naviraí) é de, aproximadamente, 2 horas e 30 minutos.

${ }^{13} \mathrm{O}$ percentual menor entre os veteranos pode ser um indicativo de que, no decorrer dos períodos do curso ao qual o aluno se vincula, há a opção pela mudança para a cidade de Dourados. No entanto, convém ressaltar que essa tendência só pode ser analisada a partir de um período e não apenas de um único ano.

${ }^{14} \mathrm{Na}$ UFGD fica sob responsabilidade do aluno atualizar o seu endereço no sistema de cadastro discente. Nesse sentido, a análise dos dados dessa instituição não permite a comparação do atual endereço do discente com aquele informado ainda no vestibular.
}

Estudos Geográficos, Rio Claro, 15(1): 62-87, jan./jun. 2017 (ISSN 1678_698X)

http://www.periodicos.rc.biblioteca.unesp.br/index.php/estgeo 
termos de tamanho demográfico, têm destaque em relação à formação do público discente da UFGD.

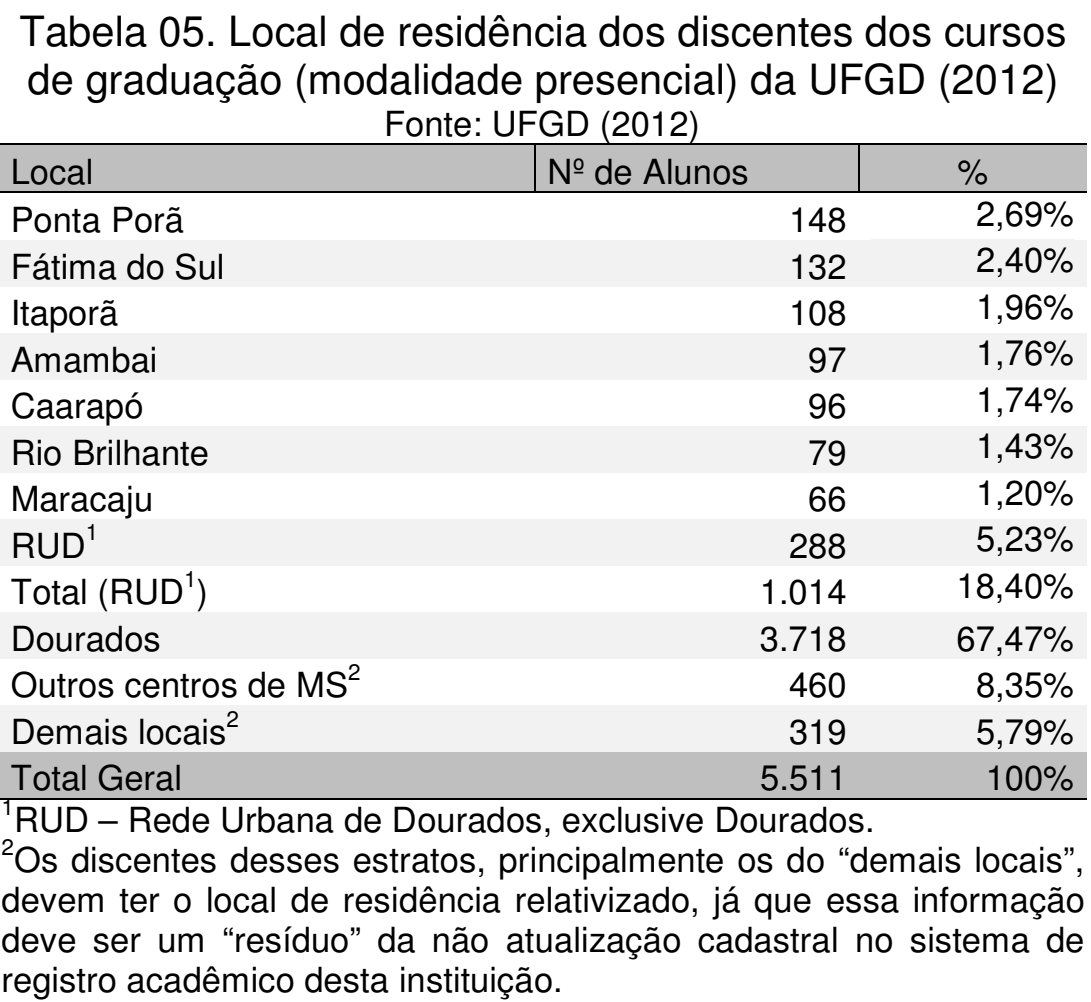

Por sua vez, a UEMS, com um total de 2.127 discentes, tem $23,37 \%$ de seus alunos residindo em cidades da rede urbana de Dourados (IBGE/Regic, 2008) - ver Tabela 06 . Já os outros municípios do estado de Mato Grosso do Sul, perfazem um total de $7,24 \%$ de discentes matriculados. Desse total, destacam-se os municípios de Campo Grande, Nova Alvorada do Sul e Jardim que, apesar de não estarem na rede urbana de Dourados, aparecem como origem de discentes que se vinculam às instituições de ensino superior. Os percentuais mais representativos são Fátima do Sul $(4,33 \%)$, Ponta Porã $(2,44 \%)$, Caarapó $(2,44 \%)$, Itaporã $(2,07 \%)$ e Amambai $(1,79 \%)$.

Apesar das posições se alterarem, na UFGD, as cinco origens mais representativas da rede urbana de Dourados são as mesmas. Destaca-se a representatividade de Fátima do Sul que, na UFGD, ocupa a segunda posição em relação ao número de alunos e, na UEMS, passa a ser a origem mais representativa.

A representatividade dos discentes da UEMS que moram em Dourados $(69,21 \%)$ é superior àquela verificada entre os discentes da UFGD $(67,47 \%)$ e da UNIGRAN (65,92\%). A representatividade dos alunos advindos dos centros da rede urbana é mais significativa na UNIGRAN ${ }^{15}$, que possui $32,86 \%$ de seu público

\footnotetext{
${ }^{15}$ Esse número advém da soma entre os estratos "Região da Grande Dourados" e "Outras" da Tabela .

Estudos Geográficos, Rio Claro, 15(1): 62-87, jan./jun. 2017 (ISSN 1678-698X) 
formado por discentes que, possivelmente, se deslocam diariamente para estudar em Dourados. Na UEMS (23,37\%) e na UFGD (18,40\%).

Tabela 06. Local de residência dos

discentes dos cursos de graduação

modalidade presencial da UEMS (2013)

\begin{tabular}{|c|c|c|}
\hline Local & № de Discentes & $\%$ \\
\hline Fátima do Sul & 92 & $4,33 \%$ \\
\hline Ponta Porã & 52 & $2,44 \%$ \\
\hline Caarapó & 52 & $2,44 \%$ \\
\hline Itaporã & 44 & $2,07 \%$ \\
\hline Amambai & 38 & $1,79 \%$ \\
\hline Rio Brilhante & 35 & $1,65 \%$ \\
\hline Maracaju & 35 & $1,65 \%$ \\
\hline $\mathrm{RUD}^{1}$ & 149 & $7,01 \%$ \\
\hline Total (RUD $\left.{ }^{1}\right)$ & 497 & $23,37 \%$ \\
\hline Dourados & 1.472 & $69,21 \%$ \\
\hline Outros centros do $\mathrm{MS}^{2}$ & 154 & $7,24 \%$ \\
\hline Demais Locais ${ }^{2}$ & 4 & $0,19 \%$ \\
\hline Total Geral & 2.127 & $100,00 \%$ \\
\hline $\begin{array}{l}\text { RUD - Rede Urban } \\
\text { Dourados. } \\
\text { Os discentes desses e } \\
\text { demais locais", devem } \\
\text { elativizado, já que es } \\
\text { resíduo" da não atualiz } \\
\text { egistro acadêmico desta }\end{array}$ & $\begin{array}{l}\text { de Dourados, } \\
\text { tratos, principalm } \\
\text { ter o local de } \\
\text { a informação de } \\
\text { ção cadastral no } \\
\text { instituicão. }\end{array}$ & $\begin{array}{l}\text { exclusive } \\
\text { ente os do } \\
\text { residência } \\
\text { e ser um } \\
\text { sistema de }\end{array}$ \\
\hline
\end{tabular}

Fonte: UEMS (2013)

Outra contribuição à caracterização da oferta do ensino superior em Dourados em sua relação com a rede urbana é a contagem, conforme a origem, dos ônibus de transporte interurbano, que se concentram nos estacionamentos das instituições de ensino superior. Nesse sentido, a relevância de cada centro da rede urbana se mostra pelo número de veículos que fazem os deslocamentos diários.

No período matutino, a quantidade de veículos no estacionamento que serve a UNIGRAN foi maior do que aquela verificada no "estacionamento" que serve a Cidade Universitária" ${ }^{17}$. Enquanto no primeiro, havia 24 veículos, entre ônibus, microônibus e vans, no segundo havia apenas 06 , totalizando 30 veículos nesse período ver Quadro 03.

Em relação às origens desses veículos, enquanto na UNIGRAN havia veículos de 11 locais diferentes ${ }^{18}$, na Cidade Universitária, havia de 05 . Os

\footnotetext{
${ }^{16} \mathrm{O}$ termo vem acompanhado de aspas porque se trata de um estacionamento improvisado e que tem gerado certos transtornos tanto para os alunos que se utilizam desse meio de transporte como para os motoristas, que lidam com a falta de infraestrutura do local (não há local de permanência para os motoristas, não há sanitários, não há iluminação e o piso do local recebeu apenas uma camada de pedregulhos que, em dias de chuva, não é eficaz, formando poças de lama).

${ }^{17}$ A Cidade Universitária é uma área que dista, aproximadamente, $15 \mathrm{~km}$ do centro da cidade de Dourados e é ocupada pela UEMS e pela UFGD, e onde se concentram a maior parte das aulas da dos cursos de graduação dessas instituições.

${ }_{18}$ Vale salientar que o número de ônibus estacionados nas instituições em Dourados não revela como os discentes se distribuem nas instituições, uma vez que há estacionamento apenas em duas delas, condição que acentua os fluxos na direção de dois pontos da cidade. Vale salientar, ainda, que a origem deve ser trabalhada Estudos Geográficos, Rio Claro, 15(1): 62-87, jan./jun. 2017 (ISSN 1678—698X)
} 
deslocamentos mais expressivos são advindos de Vicentina/Fátima do $\mathrm{Sul}^{19}(5$ ônibus), Caarapó (04 ônibus), Rio Brilhante (04 ônibus) e Maracaju (03 ônibus). O que se diferencia entre as origens são os veículos vindos dos distritos de Dourados: Indápolis (01 ônibus) e Vila Vargas (01 micro-ônibus e 01 van).

Quadro 03. Origem dos veículos de transporte de discentes (interurbano) - período matutino (2013)

\begin{tabular}{|c|c|c|c|}
\hline \multirow{2}{*}{ Período } & \multicolumn{3}{|c|}{ UNIGRAN } \\
\hline & Origem & Quantidade & Tipo do Veículo \\
\hline \multirow{14}{*}{ 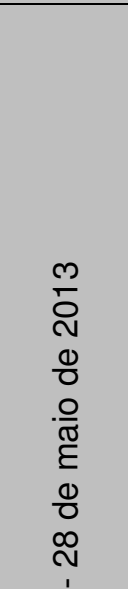 } & Caarapó & 4 & Ônibus \\
\hline & Maracaju & 3 & Ônibus \\
\hline & Vicentina/Fátima do Sul & 3 & Ônibus \\
\hline & Rio Brilhante & 3 & Ônibus \\
\hline & Itaporã & 2 & Ônibus \\
\hline & Ponta Porã & 2 & Ônibus \\
\hline & Naviraí & 1 & Ônibus \\
\hline & Glória de Dourados & 1 & Micro-ônibus \\
\hline & \multirow{2}{*}{ Angélica } & 1 & Micro-ônibus \\
\hline & & 1 & Ônibus \\
\hline & \multirow{2}{*}{ Vila Vargas (distrito de Dourados) } & 1 & Micro-ônibus \\
\hline & & 1 & Ônibus \\
\hline & Juti & 1 & Van \\
\hline & Total & 24 & \\
\hline \multirow{9}{*}{ 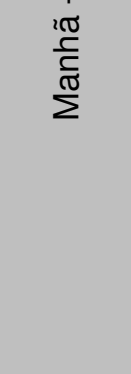 } & \multicolumn{3}{|c|}{ Cidade Universitária } \\
\hline & Origem & Quantidade & Tipo do Veículo \\
\hline & Vicentina/Fátima do Sul & 2 & Ônibus \\
\hline & Caarapó & 1 & Ônibus \\
\hline & Indápolis (distrito de Dourados) & 1 & Ônibus \\
\hline & Rio Brilhante & 1 & Ônibus \\
\hline & Naviraí & 1 & Van \\
\hline & Total & 6 & \\
\hline & Total Geral & 30 & \\
\hline
\end{tabular}

As cidades mais distantes, dentre as listadas no Quadro 03, são Naviraí (140 km), Ponta Porã (120 km) e Maracaju (70 km), que levam, em média , $2 \mathrm{~h}$ e $30 \mathrm{~min}$, $2 \mathrm{~h}$ e $10 \mathrm{~min}$ e $1 \mathrm{~h}$ e $45 \mathrm{~min}$, respectivamente, para fazer o trajeto até Dourados.

No período vespertino, assim como no matutino, no estacionamento da UNIGRAN havia mais veículos (04 no total) do que na Cidade Universitária (apenas 01) - ver Quadro 04. Durante o dia, é notória a diminuição da quantidade de veículos (05 no total), haja vista que a maioria dos cursos é ofertada no período noturno.

\footnotetext{
em conjunto, mesmo se os veículos se utilizam de estacionamentos distintos, ou seja, é necessário sempre considerar a somatória de veículos presentes nas duas áreas de uma única origem, pois a presença do veículo em um dos estacionamentos não significa a exclusividade da vinculação dos discentes transportados.

${ }^{19}$ A origem desses deslocamentos é tratada em conjunto pela proximidade em que as cidades de Fátima do Sul e Vicentina possuem e pelo fato de a principal empresa que transporta os discentes desses locais ser a mesma, que iniciou suas atividades em Vicentina e, atualmente, tem escritório em Fátima do Sul e garagem (manutenção e logística) em Dourados. Assim como acontece em Vicentina e em Fátima do Sul, há outros locais que são servidos por transporte interurbano que têm discentes em mais de um município, condição que é gerada pelo traçado da rodovias e pela incapacidade das empresas em fazer lotação em um único local, exigindo a ampliação da área sobre a qual atua.
}

Estudos Geográficos, Rio Claro, 15(1): 62-87, jan./jun. 2017 (ISSN 1678_698X)

http://www.periodicos.rc.biblioteca.unesp.br/index.php/estgeo 
Mesmo para os cursos que se estendem para o período vespertino (curso integral), não há a necessidade de transporte interurbano, já que o deslocamento já se deu no período matutino.

Em relação à origem, os veículos que estavam nos estacionamentos eram de Caarapó, Maracaju e Rio Brilhante. Outra característica das empresas que permanecem em Dourados é o trânsito entre um estacionamento e outro, já que um único veículo consegue atender os discentes de mais de uma instituição. Portanto, é comum um mesmo veículo, em horários diferentes do dia, estar em um ou outro estacionamento.

Quadro 4. Origens dos veículos de transporte de discentes (interurbano) período vespertino (2013)

\begin{tabular}{|c|c|c|c|}
\hline \multirow{2}{*}{ Período } & \multicolumn{3}{|c|}{ UNIGRAN } \\
\hline & Origem & Quantidade & Tipo do Veículo \\
\hline \multirow{4}{*}{$\begin{array}{l}\frac{0}{0} \\
. \frac{0}{\pi} \\
\varepsilon\end{array}$} & \multirow{2}{*}{ Maracaju } & 1 & Ônibus \\
\hline & & 1 & Van \\
\hline & Rio Brilhante & 1 & Micro-ônibus \\
\hline & Caarapó & 1 & Ônibus \\
\hline \multirow{6}{*}{ 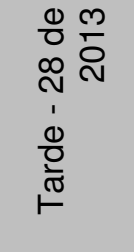 } & Total & 4 & \\
\hline & \multicolumn{3}{|c|}{ Cidade Universitária } \\
\hline & Origem & Quantidade & Tipo do Veículo \\
\hline & Caarapó & 1 & Ônibus \\
\hline & Total & 1 & \\
\hline & Total Geral & 5 & \\
\hline
\end{tabular}

Fonte: Moreno (2013)

O período noturno é aquele que possui o número maior de veículos, já que é nesse período que os fluxos ocorrem com maior intensidade. O estacionamento da UNIGRAN, nos três períodos, superou o da Cidade Universitária em relação ao número de veículos - ver Quadro 05. Essa condição, se fosse a única variável, poderia indicar que a UNIGRAN é a instituição mais procurada pelos alunos do entorno. No entanto, como já mencionado, há alguns aspectos que podem relativizar essa questão como, por exemplo, a mudança dos discentes da área de influência para Dourados assim que ingressam nos cursos de nível superior e o trânsito de veículos entre as instituições e os estacionamentos.

O destaque do período noturno pode ser reforçado apenas pela quantidade de veículos presentes na UNIGRAN (46 no total), que é superior à quantidade total de veículos dos períodos matutino e vespertino juntos. No entanto, a maior diferença entre o número de veículos se deu nos dois primeiros períodos do dia, já que a Cidade Universitária apresentou a média de 01 veículo para 04 dos presentes na UNIGRAN. Já no período noturno, apesar da expressividade numérica, a representatividade da quantidade de veículos na Cidade Universitária aumenta: para cada 01 veículo, há 2,71 na UNIGRAN.

Os locais de onde mais se deslocam alunos, considerando o número de veículos nos estacionamentos, foram Rio Brilhante (08 ônibus), Caarapó (07 ônibus), Vicentina/Fátima do Sul (07 ônibus), Naviraí (06 veículos) e Nova Alvorada do Sul (06 veículos). Dentre as origens, a cidade que é mais próxima de Dourados é Itaporã 
(cerca de $20 \mathrm{~km}$ ) e as mais distantes são Naviraí (cerca de $140 \mathrm{~km}$ ) e Amambai (cerca de $130 \mathrm{~km}$ ), cujo percurso leva, em média, $2 \mathrm{~h}$ e $20 \mathrm{~min}$ e $2 \mathrm{~h}$ e $30 \mathrm{~min}$.

Quadro 05. Origens dos veículos de transporte de discentes (interurbano) - período noturno (2013)

\begin{tabular}{|c|c|c|c|}
\hline \multirow{2}{*}{ Período } & \multicolumn{3}{|c|}{ UNIGRAN } \\
\hline & Origem & Quantidade & Tipo do Veículo \\
\hline \multirow{36}{*}{ 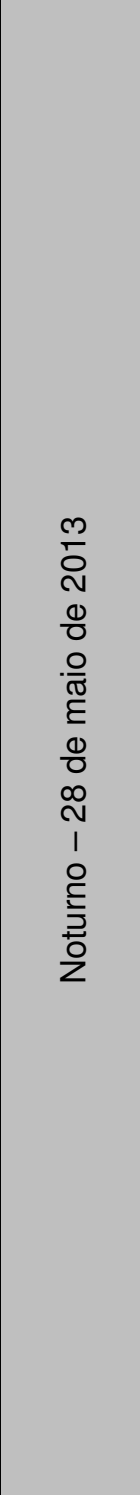 } & Maracaju & 5 & Ônibus \\
\hline & Ponta Porã & 2 & Ônibus \\
\hline & Naviraí & 5 & Ônibus \\
\hline & Itaporã & 2 & Ônibus \\
\hline & Caarapó & 4 & Ônibus \\
\hline & Glória de Dourados & 2 & Ônibus \\
\hline & Vicentina/Fátima do Sul & 5 & Ônibus \\
\hline & Angélica & 2 & Ônibus \\
\hline & Laguna Carapã & 1 & Ônibus \\
\hline & \multirow{2}{*}{ Nova Alvorada do Sul } & 1 & Van \\
\hline & & 2 & Ônibus \\
\hline & Deodápolis & 1 & Ônibus \\
\hline & Rio Brilhante & 7 & Ônibus \\
\hline & Amambai & 3 & Ônibus \\
\hline & Ivinhema & 1 & Micro-ônibus \\
\hline & Douradina & 1 & Ônibus \\
\hline & Jardim & 1 & Ônibus \\
\hline & Jatei & 1 & Ônibus \\
\hline & Total & 46 & \\
\hline & \multicolumn{3}{|c|}{ Cidade Universitária } \\
\hline & Origem & Quantidade & Tipo do Veículo \\
\hline & Vicentina/Fátima do Sul & 2 & Ônibus \\
\hline & Caarapó & 3 & Ônibus \\
\hline & Glória de Dourados & 1 & Ônibus \\
\hline & Rio Brilhante & 1 & Ônibus \\
\hline & \multirow{2}{*}{ Nova Alvorada do Sul } & 2 & Ônibus \\
\hline & & 1 & Van \\
\hline & Maracaju & 1 & Ônibus \\
\hline & Ivinhema & 1 & Ônibus \\
\hline & Angélica & 1 & Ônibus \\
\hline & Itaporã & 1 & Ônibus \\
\hline & Amambai & 1 & Ônibus \\
\hline & Douradina & 1 & Ônibus \\
\hline & Navirai & 1 & Micro-ônibus \\
\hline & Total & 17 & \\
\hline & Total Geral & 63 & \\
\hline
\end{tabular}

Fonte: Moreno (2013)

No período noturno não há veículos dos distritos de Dourados que, no período matutino, estavam nos estacionamentos das instituições. Essa ausência pode estar relacionada à localização de cada um deles, já que assumem a condição de estar Estudos Geográficos, Rio Claro, 15(1): 62-87, jan./jun. 2017 (ISSN 1678-698X) 
"no caminho", no percurso entre Dourados e outras cidades, sendo servidos pelo veículo de transporte de outros locais. Esse é o caso da Vila São Pedro e da Vila Vargas que são servidas pelas empresas de transporte que têm como origem Douradina, município limítrofe desses distritos de Dourados.

É importante destacar a presença de veículos de Jardim e de Nova Alvorada do Sul, que não se encontram dentre os municípios que compõem a rede urbana de Dourados (IBGE/Regic, 2008). O destaque em relação a Jardim $^{20}$ se refere, principalmente, à distância entre essa cidade e a cidade de Dourados, cerca de 215 $\mathrm{km}$, percurso que leva, aproximadamente, 3 horas de ônibus para ser percorrido, 0 que praticamente inviabiliza o deslocamento diário. A cidade de Jardim possui, ainda, uma unidade da UEMS que oferta 04 cursos, sendo eles: Educação Física, Geografia, Letras (Português-Inglês) e Turismo.

Já Nova Alvorada do Sul se destaca pela quantidade de veículos nos estacionamentos (06 no total), entre ônibus e vans. Essa condição se revela importante porque esse centro está entre as cidades de Dourados (aproximadamente $110 \mathrm{~km}$ ) e Campo Grande (cerca de $120 \mathrm{~km}$ ), a capital do estado. Segundo o IBGE/Regic (2008), Nova Alvorada do Sul é um Centro Local e vinculase diretamente à capital do estado, Campo Grande - funcionalmente, mais complexa e, demograficamente, maior que Dourados.

No entanto, apesar dessas condicionantes, há fluxos significativos em direção a Dourados, superando inclusive centros com os quais o IBGE/Regic (2008) considera que Dourados possui relação direta. Vale destacar que o município de Nova Alvorada do Sul possui 16.432 habitantes, dentre os quais, 12.286 residem na cidade (IBGE, 2010). Economicamente, destaca-se pela produção sulcroalcooleira. Vale registrar, ainda, que esse centro não possui nenhuma instituição com oferta de cursos de graduação na modalidade presencial ou à distância.

Nesse sentido, a análise da centralidade de Dourados, em relação ao ensino superior, ao mesmo tempo que se reafirma pelas vinculações propostas pelo IBGE/Regic (2008) - expressas pela representatividade, principalmente, dos centros de Fátima do Sul, Ponta Porã, Itaporã, Caarapó, Maracaju, Amambai, Rio Brilhante e de Naviraí em relação ao número de discentes -, deve ser relativizada para a especificidade das interações no que se refere ao ensino superior.

Isso se deve, em grande medida, à pequena expressividade dos centros no extremo Sul da rede urbana regional, que estão mais distantes de Dourados. Ainda em relação ao ensino superior, há a necessidade de incorporar os centros urbanos ao norte de Dourados em sua área de influência, já que as interações que se dão como, por exemplo, com Jardim e com Nova Alvorada do Sul ${ }^{21}$ podem determinar uma área de influência mais abrangente do que a proposta pelo IBGE/Regic (2008), se tratando das especificidades do ensino superior.

Assim, mesmo que alguns centros mantenham vínculos de diversas ordens com Dourados, em relação ao ensino superior, as interações podem não ser significativas. Por outro lado, alguns que não figuram em sua área de influência, se

\footnotetext{
${ }^{20}$ O município de Jardim possui 24.346 habitantes, dos quais 22.741 residem na cidade (IBGE, 2010). Sua economia tem fortes vinculações com a atividade turística e mantém relação direta com Guia Lopes da Laguna (Centro Local), que se distancia cerca de $5 \mathrm{~km}$, e é subordinado a Jardim (Centro de Zona B).

21 Vale destacar que as cidades de Bela Vista e de Mundo Novo, por exemplo, estão, aproximadamente, a $240 \mathrm{~km}$ e a $250 \mathrm{~km}$ de Dourados, bem mais distantes que Nova Alvorada do Sul (cerca de 110km) e até Jardim (cerca de $115 \mathrm{~km}$ ). Nesse sentido, a centralidade expressa por Campo Grande é condição para o entendimento da não subordinação desses centros a Dourados, já que a proximidade, nesse caso, não se fez determinante. Vale destacar que Jardim e Nova Alvorada do Sul estão a, aproximadamente, $240 \mathrm{~km}$ e $120 \mathrm{~km}$ de Campo Grande.
}

Estudos Geográficos, Rio Claro, 15(1): 62-87, jan./jun. 2017 (ISSN 1678_698X)

http://www.periodicos.rc.biblioteca.unesp.br/index.php/estgeo 
fazem presentes e com vinculações mais expressivas, inclusive, do que determinados centros que estão subordinados diretamente a Dourados - ver Figura 02.

Figura 02. Dourados-MS (2013) - Origem dos fluxos diários de veículos estudantis de transporte interurbano

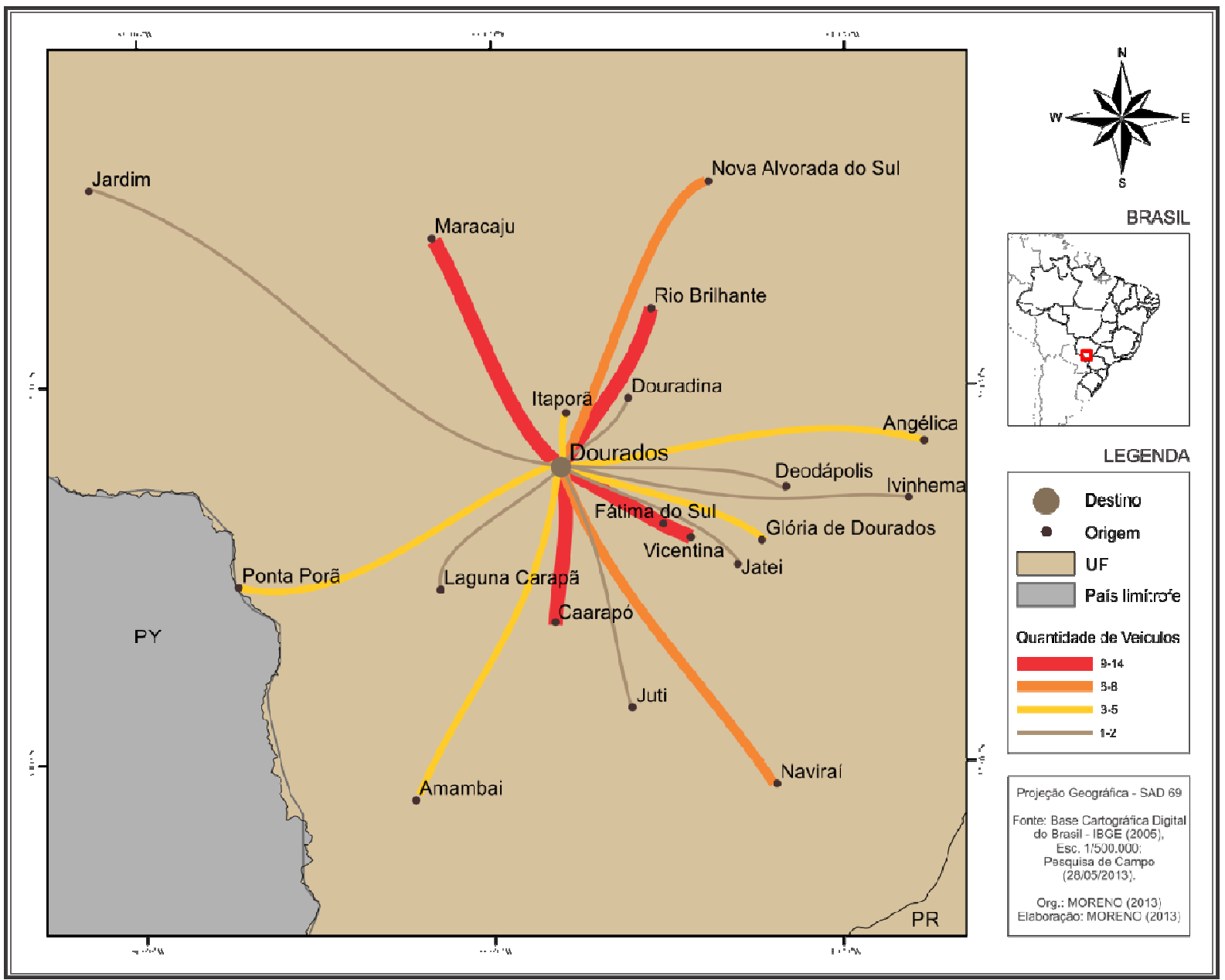

Na Figura 02 estão representados os fluxos mais significativos do transporte interurbano de discentes em direção a Dourados. Esse dado tem como referencial as informações já elencadas no Quadro 02, no Quadro 03 e no Quadro 04. Os locais mais representativos, em termos de origem, são Caarapó (14 veículos), Rio Brilhante (13 veículos), Vicentina/Fátima do Sul (12 veículos) e Maracaju (11 veículos).

Observa-se que vários centros da rede urbana de Dourados não são representados nessa figura. Isso se deve à inexistência de veículos, a partir desses centros, nos estacionamentos que servem as IES, revelando que não mantém fluxos diários de alunos em direção a Dourados.

Estudos Geográficos, Rio Claro, 15(1): 62-87, jan./jun. 2017 (ISSN 1678-698X)

http://www.periodicos.rc.biblioteca.unesp.br/index.php/estgeo 
Nesse sentido, a contabilização de veículos nos estacionamentos é um elemento para a quantificação dos fluxos diários, assim como a abrangência da área de procedência desses fluxos. Assim, para a representação da contribuição de cada centro urbano, em relação à quantidade de alunos que participam desses deslocamentos, foram subtraídos dos locais de origem aqueles que não se repetiam como origem dos veículos de transporte interurbano.

Por outro lado, os alunos oriundos daqueles municípios que não integram a rede urbana de Dourados, dos quais verifica-se a existência de transporte interurbano de discentes, foram acrescentados e considerados como uma das origens dos acadêmicos - é o caso de Jardim e o de Nova Alvorada do Sul. Portanto, como o objetivo da Figura 02 é demonstrar a expressividade do local de origem em relação aos deslocamentos de estudantes em direção a Dourados, alguns centros que figuravam na Tabela 05 e na Tabela 06 não foram considerados. Por outro lado, outros que não figuravam nas mesmas tabelas, passam a ser considerados.

É válido destacar que as origens mais representativas em relação à quantidade de veículos e em relação à quantidade de discentes são diferentes. A justificativa para que haja essa diferença consiste no fato de que as instituições privadas de Dourados não contabilizam os alunos que se deslocam diariamente. Nesse sentido, a Figura 03 revela apenas a quantidade de discentes das instituições públicas. Portanto, se os discentes das IES privadas fossem considerados, certamente haveria o reforço da expressividade de locais que são mais significativas em relação ao número de veículos. Por outro lado, essa diferença verificada dá indícios de que as interações entre o local de origem e as IES em Dourados são diferentes em relação ao ensino do setor público e ao ensino do setor privado ${ }^{22}$.

A porcentagem de estudantes da UNIGRAN que se deslocam diariamente, conforme sua avaliação institucional, é de 31,12\% (ou 1.651 discentes). Ou seja, número superior ao verificado nas instituições públicas. As instituições públicas, por sua vez, se considerados apenas os locais dos quais se deslocam diariamente os ônibus dos estacionamentos têm, aproximadamente, 1.500 alunos, sendo que na UFGD, a representatividade desses discentes, com relação ao total de alunos da instituição é de $18,05 \%$, e, na UEMS, é de $23,04 \%$. Nesse sentido, a superioridade verificada na UNIGRAN pode assegurar a variação na expressividade do local de origem dos alunos, criando consonância entre 0 número de veículos nos estacionamentos (e sua capacidade de transporte) com o total de discentes que se deslocam diariamente.

Os locais de origem mais representativos foram Fátima do Sul (224 discentes) e Ponta Porã (200 discentes). Em uma proporção menor, ainda se destacam: Itaporã (152 discentes), Caarapó (148 discentes), Amambai (135 discentes), Rio Brilhante (114 discentes) e Maracaju (101 discentes).

A partir da Figura 03, é possível diferenciar a expressividade entre Vicentina e Fátima do Sul, o que apenas pela quantidade de veículos (Figura 02) não era possível. Enquanto Vicentina possui 54 discentes vinculados às instituições públicas de Dourados, Fátima do Sul possui 224. Nesse sentido, apesar de a empresa que serve esses dois locais ser a mesma, Fátima do Sul se destaca. A relevância de Nova Alvorada do Sul, verificada em relação à quantidade de veículos (06 no total), fica aquém da expressividade em relação à quantidade de alunos (apenas 27). Nesse sentido, a incompatibilidade verificada entre a capacidade de transporte e a

\footnotetext{
${ }^{22}$ Por não ter havido acesso aos dados da FAD, não é possível indicar como essa condição se dá nessa instituição.

Estudos Geográficos, Rio Claro, 15(1): 62-87, jan./jun. 2017 (ISSN 1678-698X)
}

http://www.periodicos.rc.biblioteca.unesp.br/index.php/estgeo 
quantidade de alunos transportados pode ser resolvida a partir da contabilização dos alunos das instituições privadas que são oriundos desse local.

Figura 03. Dourados-MS (2013) - Origem dos fluxos diários de discentes das instituições públicas

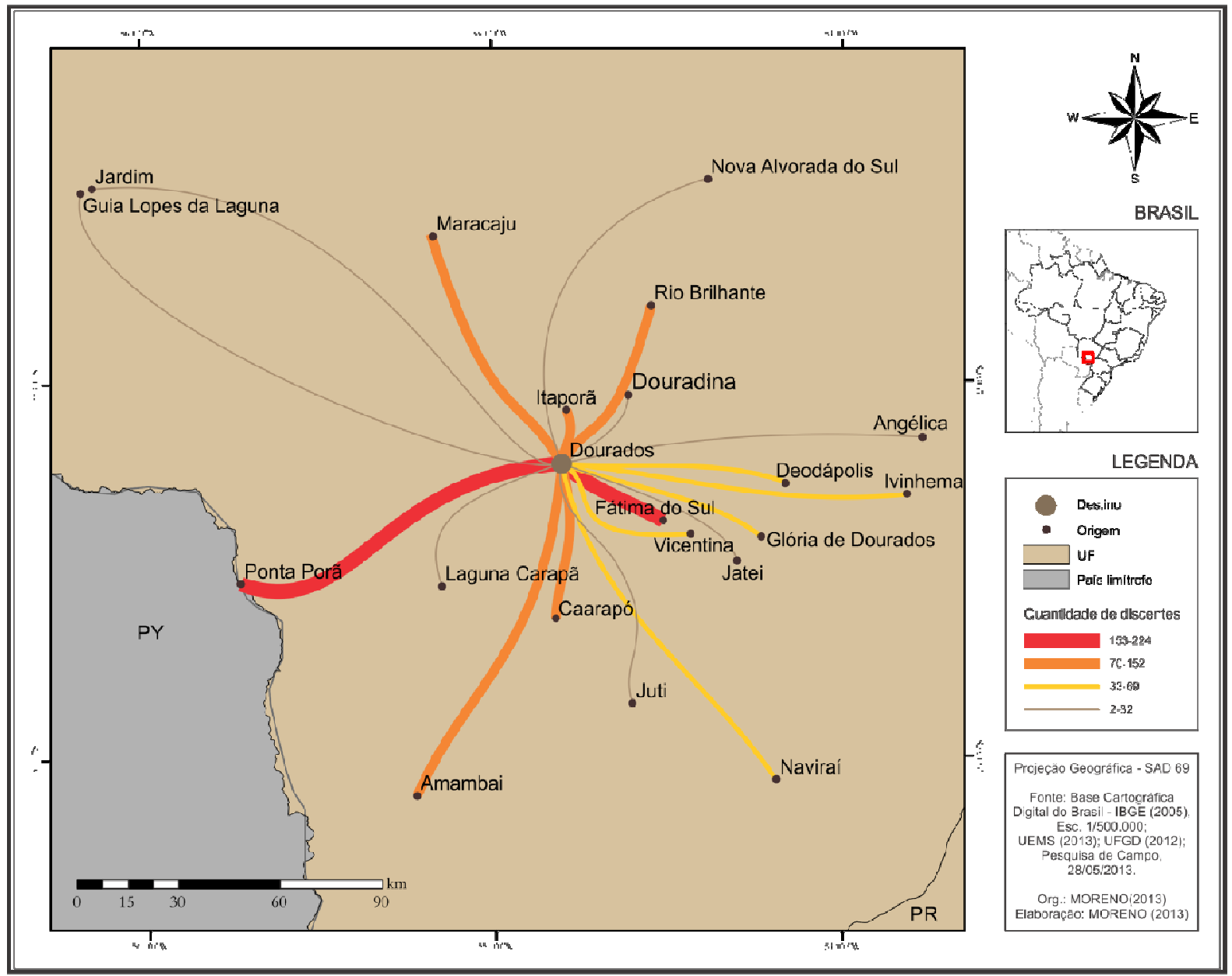

Assim como Nova Alvorada do Sul, Guia Lopes da Laguna e Jardim, apesar de não fazerem parte da rede urbana de Dourados, em relação ao ensino superior, mantêm fluxos diários de discentes. Nesse sentido, entendemos que há a necessidade de incorporar essas origens como parte da área de influência de Dourados, com relação ao ensino superior. Como já adiantamos, Guia Lopes da Laguna e Jardim foram consideradas em conjunto pela proximidade das duas cidades. Enquanto Jardim possui 28 alunos matriculados nas IES públicas de Dourados, Guia Lopes da Laguna possui 13. Esses locais superam, por exemplo, Juti e Angélica, que se vinculam diretamente a Dourados, no entanto, têm apenas 09 e 02 discentes, respectivamente, que se deslocam diariamente.

Considerando essas premissas, é válido salientar que essa leitura se limita aos fluxos diários que ocorrem, seja no interior da rede urbana, seja para além dela.

Estudos Geográficos, Rio Claro, 15(1): 62-87, jan./jun. 2017 (ISSN 1678-698X) 
No entanto, os estudantes vindos da área de influência nem sempre optam pelos deslocamentos diários, uma vez que uma parcela tem condições de se mudar para a cidade que estuda. Interfere nessa escolha, a relação do tempo de deslocamento diário para estudar, disponibilidade de trabalho na cidade de origem, horário de oferta do curso de graduação, condição socioeconômica etc. A dinâmica, nesse sentido, conduz à articulação entre escalas, que vai das mais abrangentes (sobretudo o regional) àquela mais restrita (o intraurbano - o local que concentra $e$ recebe esse contingente populacional).

\section{CONSIDERAÇÕES FINAIS}

Aqui é valido retomar duas importantes questões já abordadas. Por sua vez, como contribuição para outras pesquisas e/ou para não limitar as possibilidades de leitura sobre a temática, a partir daquela realizada aqui, são propostas algumas indicações de desdobramentos de análise.

A primeira questão, nesse sentido, tem relação com as expressividades quantitativa (revelada no número de cursos e quantidade de vagas) e qualitativa (revelada pela diversidade de cursos) da oferta do ensino superior em Dourados. Mesmo ofertando 9.315 vagas distribuídas em 87 cursos de graduação e concentrando $57,24 \%$ de toda a oferta de ensino superior da rede urbana ${ }^{23}$, essa condição não se assegura estritamente por demandas locais, mas se configura a partir da articulação da demanda local com a regional.

A segunda questão, por sua vez, tem relação com a delimitação ou recorte espacial. Optou-se, inicialmente, pela delimitação trazida pela Região de Influência das Cidades (IBGE, 2008) que, se tratando, especificamente, do ensino superior e da rede urbana regional de Dourados, apresentou algumas nuances para a análise, sobretudo aquelas percebidas a partir do fluxo diário de estudantes. Os fluxos diários de discentes que se vinculam às IES de Dourados, percebidos a partir dos veículos presentes nos estacionamentos da UNIGRAN e da Cidade Universitária, revelam que tais ligações vão, em parte, além daquelas dadas pela Região de Influência das Cidades (IBGE, 2008).

A partir dos centros mais distantes da rede urbana de Dourados, sobretudo aqueles do extremo sul do estado de Mato Grosso do Sul e do extremo noroeste do estado do Paraná, não ocorrem deslocamentos diários. Por outro lado, alguns centros urbanos localizados ao norte de Dourados (como é o caso de Nova Alvorada e de Jardim), e que não fazem parte de sua rede urbana regional, mantêm fluxos diários de discentes, revelando vinculações importantes e mais significativas inclusive do que aquelas provenientes de centros que se vinculam diretamente como, por exemplo, Angélica e Juti. Isso revela que os movimentos, processos e/ou dinâmicas analisados são determinantes na delimitação e não o contrário.

Assim, devido à complexidade de relações, articulações e fluxos estabelecidos, e para a formulação de outras leituras acerca do "ensino superior", que pelo recorte temático ou metodológico não foram privilegiadas aqui, indicam-se possíveis desdobramentos de pesquisas:

a. Dos fluxos de estudantes que não ocorrem diariamente. A área de influência de Dourados, ou de outra cidade média qualquer, em relação ao ensino superior, se demonstra mais ampla do que aquela verificada a partir

\footnotetext{
${ }^{23}$ Juntos, os demais ofertam 65 cursos e 4.588 vagas

Estudos Geográficos, Rio Claro, 15(1): 62-87, jan./jun. 2017 (ISSN 1678-698X)

http://www.periodicos.rc.biblioteca.unesp.br/index.php/estgeo
} 
dos deslocamentos diários. Tais deslocamentos podem ser a expressão mais aparente, no entanto, há aquela vinculação que não está em evidência e que necessita de maiores levantamentos para ser apreendida. Nesse sentido, o levantamento da origem dos estudantes aprovados nos processos seletivos de entrada nas IES, definiria uma área de abrangência do ensino superior a partir de fluxos que vão além dos que ocorrem diariamente. $O$ Sistema de Seleção Unificada (Sisu), utilizado pelas IES públicas, certamente complexifica essa questão ao ampliar a área de atração de estudantes, uma vez que não condiciona o acesso ao ensino superior aos processos seletivos presenciais (vestibulares), que sempre requerem deslocamentos, o que certamente se coloca como um impedimento à determinada parcela da população.

b. Do ensino superior na modalidade à distância, que traz um elemento diferenciado para a análise, uma vez que os polos e a oferta das IES avançam cada vez mais no território nacional e para além dele. Essa condição dada pelo meio técnico-científico-informacional e pelos fluxos imateriais, conecta cada vez mais pontos do território, pressupondo uma articulação escalar.

c. Das redefinições intraurbanas reveladas a partir da presença das IES. $\mathrm{Na}$ escala da cidade os fluxos se desdobram em redefinições significativas imprimem mudanças como, por exemplo, no traçado e na hierarquia de vias de circulação, na lógica das localizações de equipamentos comerciais e de lazer e, principalmente, na produção - concentrada em determinadas áreas da cidade - de habitação destinada ao aluguel para o público universitário ${ }^{24}$. Os processos e as dinâmicas desencadeadas pela oferta do ensino superior contribuem ainda, direta ou indiretamente, para a dinamização do comércio e serviços, assim como, para a dinamização do mercado imobiliário que, por sua vez, retroalimenta outros processos e dinâmicas na cidade.

Esses desdobramentos indicam a importância da análise interescalar, tendo em vista que as dinâmicas relativas à oferta do ensino superior não são/estão restritas a determinadas parcelas do território, sobretudo, quando se pensa na modalidade à distância, que vem complexificando e alterando o conteúdo da oferta e exigindo das IES adequações técnicas e logísticas.

\section{REFERÊNCIAS BIBLIOGRÁFICAS}

CALIXTO, Maria José Martinelli Silva. O papel exercido pelo poder público local na (re)definição do processo de produção, apropriação e consumo do espaço urbano em Dourados-MS. Presidente Prudente, 2000. 295f. Tese (Doutorado em Geografia) - FCT/UNESP.

CALIXTO, Maria José Martinelli Silva. 0 processo de consolidação da centralidade de Dourados-MS na rede urbana: uma contribuição para a análise de

\footnotetext{
${ }^{24}$ Tais residências são em sua maioria compactas, geminadas, térreas e/ou vertical de até quatro pavimentos. Estudos Geográficos, Rio Claro, 15(1): 62-87, jan./jun. 2017 (ISSN 1678—698X) 
uma cidade média. Rio de Janeiro, 2011. 117 f. Relatório (Pós-Doutorado em Geografia) - IGEO/UFRJ.

CENTRO UNIVERSITÁRIO DA GRANDE DOURADOS - UNIGRAN. Avaliação institucional realizada no ano 2011.

CORREAA, Roberto Lobato. 1996. Trajetórias Geográficas. 4. ed. Rio de Janeiro: Bertrand Brasil, 2010.

CORRÊA, Roberto Lobato. Construindo o conceito de cidade média. In: SPOSITO, Maria Encarnação Beltrão (org.). Cidades médias: espaços em transição. 1. ed. São Paulo: Expressão Popular, 2007a, p.23-33.

CORRÊA, Roberto Lobato. Diferenciação sócio espacial, escala e práticas espaciais. Cidades. Presidente Prudente, v. 4, n. 6, jan./dez. 2007b, p.61-72.

ELIAS, Denise. Agricultura e produção de espaços urbanos não metropolitanos: notas teórico-metodológicas. In: SPOSITO, Maria Encarnação Beltrão (org.). Cidades médias: espaços em transição. 1. Ed. - São Paulo: Expressão Popular, 2007, p.113-138.

E-MEC, Sistema de Regulação do Ensino Superior. Ministério da Educação. Disponível em: http://emec.mec.gov.br/. Acesso em agosto de 2015.

INSTITUTO BRASILEIRO DE GEOGRAFIA E ESTATÍSTICA (IBGE). Censo demográfico de 2010. Versão Digital (planilha eletrônica).

INSTITUTO BRASILEIRO DE GEOGRAFIA E ESTATÍSTICA (IBGE). Região de Influências das cidades 2007 (REGIC). IBGE: Rio de Janeiro, 2008.

MORENO, Bruno Bomfim. O "grande" como solução à identificação regional: ampliações e retrações das delimitações da região de Dourados-MS. História em Reflexão - Revista Eletrônica de História, Dourados, v. 6, n. 12, p. 1-26, jul./dez. 2012. Disponível em: http://www.historiaemreflexao.ufgd.edu.br. Acesso em: 20 de fevereiro de 2013.

MORENO, Bruno Bomfim. A centralidade do ensino superior e o processo de redefinição socioespacial em Dourados-MS. Dourados, 2013. 276f. Dissertação (Mestrado em Geografia) - FCH//Universidade Federal da Grande Dourados.

SANTOS, Milton; SILVEIRA, Maria Laura. 2001. O Brasil: território e sociedade no início do século XXI. 15. Ed. Rio de Janeiro: Record, 2011.

SILVA, Mário Cezar Tompes da. Expansão do complexo agroindustrial e o processo de mudança no espaço de Dourados. São Paulo, 1992. $275 f$. Dissertação (Mestrado em Geografia) FFLCH/USP.

SILVA, Mário Cezar Tompes da. Os novos rumos da política habitacional e o processo de urbanização de Dourados-MS. São Paulo, 2000. 371f. Tese (Doutorado em Geografia) - FFLCH/USP. 
SILVA, Valéria Ferreira da. Os papéis de Dourados-MS no contexto regional: apontamentos para a análise de uma cidade média. Dourados, 2010. $166 f$. Dissertação (Mestrado em Geografia) - FCH/Universidade Federal da Grande Dourados.

SPOSITO, Maria Encarnação B. As cidades médias e os contextos econômicos contemporâneos. In: SPOSITO, Maria Encarnação Beltrão (org.). Urbanização e cidades: perspectivas geográficas. Presidente Prudente: GAsPERR, 2001. p.609643.

SPOSITO, Maria Encarnação B. O desafio metodológico da abordagem interescalar no estudo de cidades médias no mundo contemporâneo. Cidades. Presidente Prudente: v. 3, n. 5, 2006, p.143-157.

SPOSITO, Maria Encarnação B. A produção do espaço urbano: escalas, diferenças e desigualdades socioespaciais. In: CARLOS, Ana Fani Alessandri; SOUZA, Marcelo Lopes de; SPOSITO, Maria Encarnação Beltrão (orgs.). A produção do espaço urbano: agentes e processos, escalas e desafios. 1. ed. São Paulo: Contexto, 2011, p.123-145.

SPOSITO, Maria Encarnação Beltrão Sposito et al. O Estudo das Cidades Médias Brasileiras: uma proposta metodológica. In: SPOSITO, Maria Encarnação Beltrão (org.). Cidades Médias: Espaços em Transição. 1. ed. - São Paulo: Expressão Popular, 2007, p.35-68.

UNIVERSIDADE ESTADUAL DE MATO GROSSO DO SUL - UEMS. Relatório da Comissão Própria de Avaliação (CPA). Dourados: UEMS, 2012.

UNIVERSIDADE FEDERAL DA GRANDE DOURADOS - UFGD. Auto avaliação institucional: relatório geral/2011. Dourados: UFGD, 2012.

YAMASHITA, Ana Cristina. As dinâmicas de produção no campo e seus desdobramentos em Dourados-MS. Uma contribuição para a análise de uma cidade média. Dourados, 2011. 325f. Dissertação (Mestrado em Geografia) FCH/Universidade Federal da Grande Dourados. 